\title{
Adaptive Behaviour on the Portuguese Curricula: A Comparison between Children and Adolescents with and without Intellectual Disability
}

\author{
Sofia Santos \\ Research Centre of Special Education, Department of Education, Social Sciences and Humanities, Human \\ Kinetics Faculty, UIDEF, University of Lisbon, Lisbon, Portugal \\ Email: sofiasantos@fmh.ulisboa.pt
}

Received 6 February 2014; revised 6 March 2014; accepted 13 March 2014

Copyright (C) 2014 by author and Scientific Research Publishing Inc.

This work is licensed under the Creative Commons Attribution International License (CC BY).

http://creativecommons.org/licenses/by/4.0/

(c) $\underset{\mathrm{EY}}{\mathrm{P}}$ Open Access

\begin{abstract}
The main objective of this study was to assess and compare the adaptive behaviour level of children and adolescents with and without intellectual disability trying to understand how the differences in this area could be influenced by contents and curricula. The sample was composed by 589 children and adolescents with and without intellectual disabilities (both ages 6 to 16, randomly selected from special and regular schools, respectively). The Portuguese version of Adaptive Behaviour Scale was used and administered through an interview, to a proxy who knew the individual being evaluated. Controlling for age, gender, diagnosis, and living area we found that there were statistical significant differences between both groups on most of adaptive behaviour domains in all variables. One of the conclusions is that curricula in special and regular schools differ a lot on contents and in participation activities within the community and that might be one of the causes of the non-skills acquisition by the children and adolescents with intellectual disabilities.
\end{abstract}

\section{Keywords}

Adaptive Behaviour, Curriculum, Intellectual Disability

\section{Introduction}

By definition, individuals with intellectual disability experience concomitant limitations both in IQ and adaptive behaviour measures (Schalock et al., 2007, 2010). Most of the adaptive behaviour definitions' assume the qual- 
ity of interaction between individual and the environmental demands, reflecting the person's behaviours with reference to cultural expectations (Bornstein, Giusti, Leach, \& Venuti, 2005; Borthwick-Duffy, 2007; Grossman, 1983; Tassé et al., 2012). The social modulation of behaviour is particularly relevant in social species, where individuals need to adjust their behaviours according with the social environment where they belong to (Oliveira, 2009). Therefore, adaptive behaviour measurement, focusing on the quality of daily interaction between individual and environment, will assume an essential role in the design and practice of concrete and functional interventions.

Adaptive behaviour is understood as a set of skills, learned or acquired, that allow the successfully performance in tasks and activities of independent functioning and personal-social responsibility, which through several adjustments aims to adapt to socio-cultural and age expectations, implying individual to assume his/her active role as member of a society (Luckasson \& Schalock, 2012; Nihira, 2012; Santos \& Morato, 2012). Adaptive behaviour can vary across settings and time and plays an important aspect in education for all children and adolescents with and without disabilities, being consistent with other developmental accomplishes such the academic achievements (Nihira, 2012).

Teachers and practitioners working with children and adolescents with intellectual disability are aware of the impact of these limitations on the acquisition and application of skills needed for daily life. In Portugal, there are few studies addressing the profile of functional strengths and weaknesses in persons with intellectual and developmental disabilities across specific areas of daily life. Moreover, there is limited knowledge about whether or how this functional profile of persons with intellectual disability is distinct from their peer without an intellectual disability' diagnosis. The placement of children and adolescents with intellectual disabilities in classes or multi-disability units (within regular school) in Portugal are still based exclusively on IQ measures measured by International Functionality Classification, and it has consequences in and for the future individual' development and opportunities.

At the time of this study, most children with disabilities were in special schools, away from their peers without intellectual disability, in a segregated setting. The curriculum of these schools was (more) therapeutic with more adaptations to contents. However, children were in a segregated space. On the other hand, mainstream schools were (and still are) skilled in assessing cognitive learning outcomes vs. functional and practical skills, the curriculum was normative, equal for all and unable to meet children with intellectual disability "needs, promoting childish and non-dignifying" activities for students with intellectual disability and emphasizing more academic goals (memorization of scholar contents) than the relevance of learning functional contents and its transfer for daily life (Costa et al., 1996).

Social competences and adaptive behaviours are emergent in scholar curriculum (for all). The real participation of children and adolescents with intellectual disability requires mainstreaming settings, in a daily interaction with their peers within an adapted curriculum promoting the independent functioning, equal opportunities and skills achievement (Costa et al., 1996; Santos \& Morato, 2012).

The measurement of adaptive behaviour presents multiple purposes, beyond the diagnosis: it may be also useful for the program planning because it evaluates the typical and actual behaviour (Luckasson \& Schalock, 2012; Tassé et al., 2012; Thompson et al., 2009), for the identification of strengths and weaknesses among adaptive assets and liabilities to be incorporated into supports planning (Nihira, 2012; Nihira, Leland, \& Lambert, 1993), offering information to develop habilitation training/educational programs and documenting the progress of the individual, and allowing the programs' evaluation (Nihira, 2012; Nihira, Leland, \& Lambert, 1993).

In sum, this study aims to compare the level of adaptive behaviour between children and adolescents with and without intellectual disability trying to understand how the differences in this area could be influenced by contents and curricula. Comparisons between both groups were not restricted to the overall score of adaptive behaviour, but to the domains one-by-one, to avoid the under or overestimation of the (problem) in all domains of the scale. It is part of an on-going study to evaluate and compare the adaptive behaviour of children and adolescents with and without intellectual disabilities, in order to implement an appropriate school-based intervention to promote an independent functioning of these populations.

\section{Method}

\subsection{Sample and Procedures}

The sample comprised 586 children and adolescents with and without intellectual disability 296 females; 293 
males), with ages ranging from 6 to 16 years $(M=11.95$; $S D=3.09)$. The general sample's characteristics are presented in Table 1. Children and adolescents of the sample were obtained from special (educational services) and regular schools around the country. The diagnoses of intellectual disability were already established and were selected randomly by the staff of (regular and special) schools. At the time of sampling every almost all children with intellectual disability in Portugal attended special schools, located separately from regular schools.

Each school (both special and regular) were contact previously and was sent sampling instructions. Parents and caregivers were informed about the research project and the application of the Portuguese Adaptive Behaviour Scale (PABS) happened only after they give their consent. All school directors gave their written informed consent, as well their legal guardians (parents, caregivers) for each participant. The items were applied in accordance with the guidelines of the original scale and in all cases PABS was administered through an interview, using another person's knowledge (parents, caregiver, a key worker) who knew the participant well (at least at two or three years) and “have observed the person's typical behaviour over time in multiple contexts” (Tassé et al., 2012: p. 296).

\subsection{Measures}

In order to determine students' adaptive behaviour was used PABS, based on the original version of Adaptive Behaviour Scale Residential and Community develop by Nihira, Leland \& Lambert (1993).

PABS' structure is similar to the original one, being divided in two parts and presenting the same kind of be-

Table 1. General characteristics of the study population $(\mathrm{N}=589)$.

\begin{tabular}{|c|c|c|}
\hline Characteristics & $\mathrm{N}$ & $\%$ \\
\hline \multicolumn{3}{|l|}{ Gender } \\
\hline Females & 294 & 50.2 \\
\hline Males & 292 & 49.8 \\
\hline \multicolumn{3}{|l|}{ Age } \\
\hline & 6 & 5.6 \\
\hline & 7 & 6.3 \\
\hline & 8 & 6.5 \\
\hline & 9 & 5.5 \\
\hline & 10 & 9.2 \\
\hline & 11 & 8.5 \\
\hline & 12 & 8.7 \\
\hline & 13 & 9.9 \\
\hline & 14 & 11.8 \\
\hline & 15 & 15.5 \\
\hline & 16 & 12.5 \\
\hline \multicolumn{3}{|l|}{ Diagnosis } \\
\hline “Without IDD” & 318 & 54.3 \\
\hline IDD mild $^{1}$ & 45 & 7.7 \\
\hline IDD moderate & 122 & 20.8 \\
\hline IDD severe & 47 & 8.0 \\
\hline Multiple disabilities & 54 & 9.2 \\
\hline \multicolumn{3}{|l|}{ Setting } \\
\hline Institutional Setting & 268 & $45.7 \%$ \\
\hline Mainstreaming settings & 318 & $54.3 \%$ \\
\hline
\end{tabular}

${ }^{1}$ In Portugal the classification system of mild, moderate, severe, and profound is still used, so our data were organized in this way. 
haviours grouping. Part I items are organised under 10 adaptive behaviour domains (independent functioning, physical development, economic activity, language development, numbers and time, domestic activity, pre-vocational activity, self-direction, responsibility and socialization). Responses to items' take two forms: rating the highest level of adaptive behaviour or a checklist of yes/no responses that are summed to form the item score. Part II is concerned with personality and behaviour disorders organised under eight domains (social behaviour, conformity, trustworthiness, stereotyped and hyperactive behaviour, self-abusive behaviour, sexual behaviour, social engagement, and disturbing interpersonal behaviour). Responses to items are made by rating them according to frequency (never, occasionally or frequent). The PABS goal' is to describe adaptive behaviours of the Portuguese population with intellectual disability, allowing a comprehensive evaluation of how they deal with their environmental conditions, through the analysis of behaviours, situations and daily activities.

Data analysis was performed using IBM SPSS Statistics version 20 (SPSS, Chicago, IL, USA). For all tests statistical significance was set at $p<0.05$.

\section{Results}

Psychometric properties of the Portuguese version were previously studied. Although the confirmatory model is not well established yet, the PABS seems to be applicable to this group of the population, with acceptable to high levels of internal consistency within a larger $(n=1875)$ sample. The internal consistency reliability of PABS domains (all items included) were investigated using the coefficient alpha procedure and all scores ranged from 0.81 (economic activity) to 0.98 (physical development), which were considered good or very good/excellent (Pestana \& Gageiro, 2005: p. 528; Hill \& Hill, 2009: p. 149). Using intraclass correlation coefficient, the reliability was also high for all domains ranging from 0.81 (economic activity) to 0.98 (independent functioning). Overall, PABS demonstrated good indexes of internal consistency. Were also calculated the Pearson's correlation coefficients between domains $(p<0.01)$. Part I domains' ranged from 0.53 to 0.90 showing moderate to high correlations, and part II domains presented lower correlations between them $(<0.52$, except for domains of Social Behaviour, Conformity and Trustworthiness that ranged from 0.59 to 0.70 ), although the original scores ranged from 0.81 to 0.99 (Nihira, Leland, \& Lambert, 1993) in both parts.

Descriptive statistics: Groups of children and adolescents with and without intellectual disability were compared using ANOVA. Mean values and standard-deviation of adaptive behaviour scores, for all domains, of the groups with and without intellectual disability are presented in Table 2 . There were statistical significant differences between the adaptive behaviours of children and adolescents with intellectual disability of those who had no disability diagnosed $(p<0.001)$ in all domains, as determined by one-way ANOVA: $\mathrm{F}_{\mathrm{IF}}(4,581)=273.63, p<$ $0.001 ; \mathrm{F}_{\mathrm{PD}}(4,581)=172.99, p<0.001 ; \mathrm{F}_{\mathrm{EA}}(4,581)=95.42, p<0.001 ; \mathrm{F}_{\mathrm{LD}}(4,581)=512.60, p<0.001$; $\mathrm{F}_{\mathrm{NT}}(4,581)=423.50, p<0.001 ; \mathrm{F}_{\mathrm{DA}}(4,581)=50.91, p<0.001 ; \mathrm{F}_{\mathrm{PA}}(4,581)=327.98, p<0.001 ; \mathrm{F}_{\mathrm{SD}}(4,581)=$ $325.28, p<0.001 ; \mathrm{F}_{\mathrm{R}}(4,581)=202.07, p<0.001 ; \mathrm{F}_{\mathrm{S}}(4,581)=329.52, p<0.001 ; \mathrm{F}_{\mathrm{SB}}(4,581)=44.35, p<0.001$; $\mathrm{F}_{\mathrm{C}}(4,581)=7.54, p<0.001 ; \mathrm{F}_{\mathrm{T}}(4,581)=17.20, p<0.001 ; \mathrm{F}_{\mathrm{SHB}}(4,581)=62.85, p<0.001 ; \mathrm{F}_{\mathrm{SexB}}(4,581)=10.79$, $p<0.001 ; \mathrm{F}_{\mathrm{SAB}}(4,581)=32.94, p<0.001 ; \mathrm{F}_{\mathrm{SE}}(4,581)=31.98, p<0.001 ; \mathrm{F}_{\mathrm{IPB}}(4,581)=59.94, p<0.001$. These findings seem to support the ability of PABS to discriminate both groups, supporting the original author's findings (Nihira, Leland, \& Lambert, 1993): mean scores of the group with intellectual disability are sufficiently below the average scores of the group without intellectual disability, and that differences in the mean scores of the two groups are statistically significant $(p<0.01)$ on adaptive behaviour scores. Post hoc analyses was performed to analyse where the differences lies. Children and adolescents without intellectual disability scored always higher comparing with the other groups. The same was true when comparing children with limited need of supports (at the time of application the diagnosis was "mild") with the other groups with more need of supports.

On the other hand, the groups "with profound ID" and "multiple disabilities" show no statistical significant differences, which points out for the similarity of adaptive behaviours between these two groups.

\section{Discussion}

The purpose of this study was to assess and compared the adaptive behaviour level of children and adolescents with and without intellectual disability trying to understand how the differences in this area could be incorporated in scholar contents and curricula. To our knowledge, this study is the first that tried to identify and compare adaptive behaviours among a sample of Portuguese children and adolescents with (and without) intellectual disability. 
Table 2. Means, standard-deviations and scheffe test scores of PABS domains scores for groups “with” and “without” ID.

\begin{tabular}{|c|c|c|c|c|c|c|c|c|c|c|}
\hline Domains & $\begin{array}{l}\text { Group } \\
\text { with ID }\end{array}$ & $\begin{array}{l}\text { Group } \\
\text { without } \\
\text { ID }\end{array}$ & $t$-student & $\begin{array}{l}\text { Group with } \\
\text { "mild” ID }\end{array}$ & $\begin{array}{l}\text { Scheffe test } \\
\quad \text { (mild - } \\
\text { moderate) }\end{array}$ & $\begin{array}{l}\text { Group with } \\
\text { "moderate" } \\
\text { ID }\end{array}$ & $\begin{array}{l}\text { Scheffetest } \\
\text { (moderate - } \\
\text { profound) }\end{array}$ & $\begin{array}{l}\text { Group with } \\
\text { "profound" } \\
\text { ID }\end{array}$ & $\begin{array}{l}\text { Group with } \\
\text { multiple } \\
\text { disability }\end{array}$ & $\begin{array}{l}\text { Scheffetest } \\
\text { (profound - } \\
\text { multiple dis) }\end{array}$ \\
\hline IF & $\begin{array}{c}57.11 \pm \\
39.16\end{array}$ & $\begin{array}{c}108.66 \pm \\
11.3\end{array}$ & $<0.01$ & $89.04 \pm 24.0$ & $<0.01$ & $70.35 \pm 35.28$ & $<0.01$ & $29.55 \pm 26.09$ & $24.61 \pm 28.18$ & 0.87 \\
\hline PD & $\begin{array}{c}26.95 \pm \\
11.4\end{array}$ & $\begin{array}{c}37.55 \pm \\
0.66\end{array}$ & $<0.01$ & $34.02 \pm 7.27$ & 0.14 & $31.09 \pm 8.08$ & $<0.01$ & $21.0 \pm 11.92$ & $16.87 \pm 11.06$ & 0.03 \\
\hline EA & $\begin{array}{l}2.7 \pm \\
5.75\end{array}$ & $\begin{array}{c}12.13 \pm \\
6.51\end{array}$ & $<0.01$ & $4.75 \pm 6.53$ & 0.98 & $4.02 \pm 6.90$ & $<0.01$ & $0.00 \pm 0.00$ & $0.37 \pm .1 .66$ & 0.99 \\
\hline LD & $\begin{array}{c}21.07 \pm \\
14.46\end{array}$ & $\begin{array}{c}49.42 \pm \\
2.03\end{array}$ & $<0.01$ & $35.04 \pm 10.3$ & $<0.01$ & $23.76 \pm 14.20$ & $<0.01$ & $11.36 \pm 8.75$ & $11.81 \pm 9.16$ & 0.99 \\
\hline NT & $\begin{array}{c}4.41 \pm \\
6.47\end{array}$ & $\begin{array}{c}18.7 \pm \\
2.65\end{array}$ & $<0.01$ & $9.08 \pm 6.51$ & $<0.01$ & $5.03 \pm 6.74$ & $<0.01$ & $1.17 \pm 4.03$ & $1.12 \pm 3.62$ & 1 \\
\hline DA & $\begin{array}{c}4.60 \pm \\
6.92\end{array}$ & $\begin{array}{c}9.07 \pm \\
3.99\end{array}$ & $<0.01$ & $8.62 \pm 6.91$ & 0.14 & $6.25 \pm 7.89$ & $<0.01$ & $0.70 \pm 1.92$ & $0.96 \pm 3.01$ & 0.99 \\
\hline PPA & $\begin{array}{c}3.82 \pm \\
3.20\end{array}$ & $\begin{array}{c}9.89 \pm \\
0.73\end{array}$ & $<0.01$ & $5.20 \pm 3.41$ & 0.53 & $4.54 \pm 3.55$ & $<0.01$ & $2.08 \pm 1.47$ & $2.57 \pm 2.08$ & 0.85 \\
\hline SD & $\begin{array}{c}8.39 \pm \\
7.97\end{array}$ & $\begin{array}{c}22.06 \pm \\
0.99\end{array}$ & $<0.01$ & $13.71 \pm 6.78$ & $<0.01$ & $10.04 \pm 7.99$ & $<0.01$ & $4.61 \pm 5.91$ & $3.51 \pm 6.23$ & 0.85 \\
\hline $\mathrm{R}$ & $\begin{array}{c}3.98 \pm \\
3.87\end{array}$ & $\begin{array}{c}9.11 \pm \\
0.44\end{array}$ & $<0.01$ & $6.28 \pm 3.59$ & 0.02 & $4.85 \pm 3.96$ & $<0.01$ & $1.91 \pm 2.70$ & $1.88 \pm 2.86$ & 1 \\
\hline Soc & $\begin{array}{c}14.8 \pm \\
6.80\end{array}$ & $\begin{array}{c}25.96 \pm \\
0.48\end{array}$ & $<0.01$ & $19.46 \pm 5.42$ & $<0.01$ & $16.5 \pm 6.78$ & $<0.01$ & $10.53 \pm 5.26$ & $10.75 \pm 4.57$ & 0.99 \\
\hline $\mathrm{SB}^{*}$ & $\begin{array}{c}16.72 \pm \\
17.07\end{array}$ & $\begin{array}{c}29.93 \pm \\
9.20\end{array}$ & $<0.01$ & $24.06 \pm 23.6$ & $<0.10$ & $17.68 \pm 16.56$ & 0.78 & $14.70 \pm 14.41$ & $10.16 \pm 10.26$ & 0.56 \\
\hline C & $\begin{array}{c}8.28 \pm \\
10.20\end{array}$ & $\begin{array}{c}10.13 \pm \\
3.08\end{array}$ & $<0.01$ & $10.75 \pm 13.5$ & $<0.82$ & $9.18 \pm 9.89$ & 0.78 & $7.55 \pm 10.36$ & $4.81 \pm 5.96$ & 0.45 \\
\hline $\mathrm{T}$ & $\begin{array}{c}3.87 \pm \\
8.14\end{array}$ & $\begin{array}{c}5.47 \pm \\
1.66\end{array}$ & $<0.01$ & $8.73 \pm 12.54$ & $<0.01$ & $4.04 \pm 6.93$ & 0.13 & $1.57 \pm 4.27$ & $1.44 \pm 3.89$ & 1 \\
\hline SHB & $\begin{array}{c}6.78 \pm \\
8.61\end{array}$ & $\begin{array}{c}0.07 \pm \\
0.47\end{array}$ & $<0.01$ & $1.91 \pm 4.38$ & $<0.01$ & $6.93 \pm 8.67$ & 0.38 & $8.91 \pm 8.85$ & $8.57 \pm 9.52$ & 0.99 \\
\hline SB & $\begin{array}{c}1.11 \pm \\
3.07\end{array}$ & $\begin{array}{c}0.00 \pm \\
0.00\end{array}$ & $<0.01$ & $1.27 \pm 4.35$ & 0.97 & $0.99 \pm 2.27$ & 0.86 & $1.40 \pm 3.40$ & $1.00 \pm 3.15$ & 0.91 \\
\hline SAB & $\begin{array}{c}1.57 \pm \\
3.04\end{array}$ & $\begin{array}{c}0.00 \pm \\
0.00\end{array}$ & $<0.01$ & $0.29 \pm 0.89$ & $<0.05$ & $1.34 \pm 2.78$ & $<0.01$ & $2.68 \pm 3.53$ & $2.20 \pm 3.79$ & 0.84 \\
\hline SE & $\begin{array}{c}5.32 \pm \\
6.49\end{array}$ & $\begin{array}{c}1.86 \pm \\
0.58\end{array}$ & $<0.01$ & $3.53 \pm 4.81$ & 0.85 & $4.40 \pm 5.97$ & $<0.01$ & $7.70 \pm 7.37$ & $6.79 \pm 7.26$ & 0.89 \\
\hline IDB & $\begin{array}{c}10.68 \pm \\
8.39\end{array}$ & $\begin{array}{c}3.73 \pm \\
1.05\end{array}$ & $<0.01$ & $13.73 \pm 9.78$ & $<0.01$ & $10.10 \pm 8.40$ & 0.88 & $11.17 \pm 7.60$ & $9.01 \pm 7.22$ & 0.46 \\
\hline
\end{tabular}

IF = independent functioning; PD = physical development; EA = economic activity; LD = language development; NT = numbers and time; DA = domestic activity; PVA = pre-vocational activity; $\mathrm{SD}=$ self-direction; $\mathrm{R}$ = responsibility; So = socialization; $\mathrm{SB}=$ social behavior; $\mathrm{CO}=$ conformity; $\mathrm{TR}$ = trustworthiness; $\mathrm{SHB}=$ stereotyped and hyperactive behavior; $\mathrm{SXB}=$ sexual behavior; $\mathrm{SAB}=$ self-abusive behavior; $\mathrm{SE}=$ social engagement; DIB $=$ disturbing interpersonal behavior $(p<0.01)$.

From the study a major finding appeared: children and adolescents with intellectual and developmental disabilities have significantly lower levels of adaptive behaviour than their peers typically-developed from ages 6 to 16. These findings supports others studies (Nihira, Leland, \& Lambert, 1993; Sadrossadat, Moghaddami, \& Sadrossadat, 2010; Sartawi, Al Muhairy, \& Abdat, 2011) although with a much age-broader sample (Santos \& Morato, 2012). Results were expected due to several factors: the children and adolescents with ID were all institutionalised, not living in community settings and not having the same opportunities to develop some adaptive daily competences, and being overprotected.

This situation combined with the inability to understand and play by the social rules, the limitations on selecting and discerning what cues are critical to be successful interacting with environmental demands, the re- 
duced ability to learn and cope with their peers, the lack of stimulation and difficulties in transfer the learned skills to new situations are some of the possible reasons for this study' results. The low expectations that Portuguese society in general have from persons diagnosed with intellectual disability also acts as a barrier to a full participation of these group of population: the mental age are still used. Age andsocio-cultural expectations and values (Borthwick-Duffy, 2007; Nihira, 2012; Nihira, Leland, \& Lambert, 1993) should be (re)considered in scholar curricula, based on chronological age. Most of the tasks demanding responsibility (e.g.: money management, walking alone) are performed by proxies, and students with ID do not have the opportunity to develop such skills. Language and speech disorders, as reading, writing and reasoning difficulties, usually associated with intellectual disability affect an individual ability to understand and to be understood by others and that is also visible by the scores obtained in the domains such as Language Development, Numbers and Time and Selfdirection. The medical conditions, medication' secondary effects, immunological weaknesses and consequent frequent absences by disease may also, interfere in all academic process. The memory, attention and concentration limitations often found in people with intellectual disability are also another issue to be considered.

In a more detailed analysis of results, there are, also, statistically significant difference between the groups with ID with intermittent (the so called "mild level of severity") and limited supports need ("the group with moderate intellectual disability"). The Domestic Activity, Physical Development, Pre-Vocational Activity, Conformity and Social Engagement are domains that do not show statistically significant differences between these two groups. One of the reasons is because the skills inherent to domains are not taught because people with intellectual disability do not understand it or are not allowed to perform it (e.g.: in Conformity domain, they all have to wait for their turn to lunch and they do it because proxies assure that, not because they are taught to understand social expectations). Domestic Activity and Vocational skills (such as punctuality and productivity) are not developed or stimulated because usually family or staffs in institutions are responsible for this kind of task.

Further, the groups with the extensive and permanent supports needs (profound" and "with multiple disabilities") also presents rather different results with the other groups, showing lowest levels of functioning. Another clue is that these two groups, although the difference on previous diagnosis did not show statistical significant differences, indicating that persons with intellectual disability have similar levels of skills and performance on adaptive behaviour domains. This finding supports the idea of Thompson et al. (2009) advocating a new classification by supports intensity needs rather on level of deficits. Harries et al. (2009) add the greater need of medical/health supports on both groups.

On the other hand, finding shows that adaptive behaviour increase with age (children and adolescents also differed from each other in their development of adaptive behaviour) and decreased with the "severity" of disability.

Adaptive limitations may lead to vulnerability for academic failure. Adaptive behaviours include a range of everyday skills of communication, self-care, home living, social skills, community use, self-direction, health and safety, among others that result from the interaction of the biological and cultural development with processes of learning and context specific experiences. At the moment of this study, that was not the state of art in Portugal: all children and adolescents were segregated from their peers.

One of this study limitation is the classification system (still based solely in IQ measures) and sample (small and with all participants with ID in institutional settings), who may limit the inference of cause and effect relationships. On the other hand, more research is needed on the study of factor structure of PABS in this population.

Although the existence of some studies whose findings have highlighted the importance of AB for long-term outcomes in individuals with intellectual and developmental disability (Sadrossadat et al., 2010) in Portugal there is only two studies (Santos et al., 2010; Santos \& Morato, 2012), that we are aware of, about this topic. Only in recent years emerged the need and concern to know more about the adaptive behaviour level in populations with ID and its inclusion in curricula, especially since the special education law that in 2008 stated that all children should be in regular schools and have the same opportunities.

The Portuguese educational settings were face with a new challenge: what program should be developed and what contents should be taught for promoting adaptation and participation to community and for an independent functioning of children with ID. The recent challenge is to design, implement and monitoring better and more appropriate intervention strategies to this population, to promote a more active, healthy and independent life. In order to improve the levels of daily life and community participation, it is important to identify the contents and 
skills that should be taught and enhanced at school contents.

We found consistent differences in adaptive behaviours between children and adolescents with and without intellectual disability: this research shows that children and adolescents with ID have patterns of adaptive behaviour less-developed than their typically developing peers. Adaptive behaviour should be complementary of intelligence in determining the individual's ability to cope with the environment. Therefore, our results suggest that schools' focus should be on teaching and learning independent functioning skills, as well minimizing the maladaptive behaviours that persons with intellectual disability usually exhibits. According to Tassé et al. (2012) most of adaptive behaviour skills are accomplished by general population by adulthood (that begins, by law, at the age of 18, in Portugal). Based on some findings it seems that the scale can provides guidance on identifying educational or training-related goals (Tassé et al., 2012), helping on the development of the individualized plan and person-centred plan strategies for students with intellectual disability, providing more information for individualized supports and interventions.

According to Leite (2006) and Leite (2011) Portugal faces an emergent need to break with the culture of cultural centralization and then, the need for new methods of pedagogical work, and new relationships of school knowledge with everyday life and cultural experiences of students. The author criticizes the current and rigid established curricula that ignore local and every student' realities, which goal is to educate everyone as if it they were just one, ignoring the tailor-fit curriculum or the person-centred school program and the social goals, keeping the "prêt-a-porter" curriculum. Formosinho \& Machado (2008) add also the need to change the transmissive pedagogy in an individualist teaching culture towards the new scholar diversity demanding.

Leite (2011) continue advocating the traditional curriculum: same contents, same strategies, same extension programs, same schedules, same narrow rhythms', among others, regardless each individual needs, interests and abilities.

On the other hand, the comparison of adaptive behaviours skills jointly with the supports needs over time will help teachers and practitioners to evaluate the efficacy of teaching-learning processes and positively affect the concept of intellectual disability and professional practice in Portugal. The results will allow the rethinking of Portuguese education and intervention programs' principles and goals.

\section{Conclusion}

School plays an important role in the overall development, along with family, of all children and should be aiming the quality of life of all students. Therefore, the quality and quantity of educational services and supports for students with intellectual disability have to be re-taught and re-organised in Portugal system. Portuguese schools and teachers, in general, are still no prepared to deal with students with intellectual disability-the curriculum is too much about theoretical contents rather than functional academics (Leite, 2006; Leite, 2011).

Portuguese education and intervention models should be more focus on community living adaptation factors to promote the personal independence to be engaged in community settings, instead of emphasizing strictly "academic-scholar" contents (complex mathematics, reading and writing). The question is: what is the utility of these kinds of curricular contents in the improvement of quality of life of students with intellectual disability? Educational curriculum should consider then a more flexible and functional planning, aiming the acquisition of skills that are needed immediately and in community settings, practiced in natural environments (vs. within classroom over-protected) and seen as socially important: e.g.: the adaptive behaviour. The raise of expectations that students with intellectual disability can and will learn more is also something that Portuguese educational system must work upon. It is our belief that curriculum should be designed to build every student's capacity for a full and active participation in community, within an ecological curricula and meaningful outcomes paradigm. Leite (2011) stated that if the national curriculum is the result of political and administrative options, it is essential that schools contextualize it according to every student, within a community, needs and preferences: i.e., environmental adequation. Further, "differentiate is not only reducing or simplifying curriculum: is define strategically individual learning paths, which allow each student to progress in their curriculum, aiming the success" (Leite, 2011: p. 20), during and post school. To sum up, to find out the effectiveness and appropriate intervention approaches that promote support optimal functioning across childhood and adolescence- $\mathrm{a}$ creative education.

With the introduction of new inclusive law (Decree-Law 3/2008) it is recommended that others studies, on the scholar population, with and without intellectual disability, be conducted to analyze the possible differences in adaptive behaviours within institutional vs. natural environments as reported in several studies (Larson, Lakin, 
\& Hill, 2012; Lerman, Apgar, \& Jordan, 2005; Saloviita, 2002). Another study that should be correlating IQ measures with adaptive behaviours scores to confirm (or not) the first diagnosis made, based solely in intelligence tests.

\section{References}

Bornstein, M., Giusti, Z., Leach, D., \& Venuti, P. (2005). Maternal Reports of Adaptive Behaviours in Young Children: Urban-Rural and Gender Comparisons in Italy and United States. Infant Child Development, 14, 403-424. http://dx.doi.org/10.1002/icd.414

Borthwick-Duffy, S. (2007). Adaptive Behavior. In Jacobson, J., Mulick, J., \& Rojahn, J. (Eds.), Handbook of Intellectual and Developmental Disabilities-Issues in Clinical Child Psychology. Springer, 279-293.

Costa, A. M. et al. (1996). Currículos Funcionais-Suacaracterização. Instituto de Inovação Educacional: Desenvolvimento Curricular na Educação Básica. Vol. 1, Lisboa.

Formosinho, J., \& Machado, J. (2008). Currículo e Organização: As equipas educativas como modelo de organização pedagógica. Currículosem Fronteiras, 8, 5-16.

Grossman, H. (1983). Classification in Mental Retardation. Washington DC: AAMD, EUA.

Harries, J., Guscia, R., Nettelbeck, T., \& Kirby, N. (2009). Impact of Additional Disabilities on Adaptive Behavior and Support Profiles for People with Intellectual Disabilities. American Journal on Intellectual and Developmental Disability, 114, 237-253. http://dx.doi.org/10.1352/1944-7558-114.4.237-253

Hill, M., \& Hill, A. (2009). Investigação por Questionário. Edições Sílabo.

Larson, S., Lakin, C., \& Hill, S. (2012). Behavioral Outcomes of Moving from Institutional to Community Living for People with Intellectual and Developmental Disabilities: U.S. Studies form 1977 to 2010. Research \& Practice for Persons with Severe Disabiliies, 37, 235-246. http://dx.doi.org/10.2511/027494813805327287

Leite, C. (2008). Políticas de Currículo em Portugal e (IM)Possibilidades da Escola se assumir como uma instituição curricularmente inteligente. Currículosem Fronteiras, 6, 67-81.

Leite, T. (2011). Currículo e Necessidades Educativas Especiais. ColeçãoIndução e Desenvolvimento Profissional Docente. Universidade de Aveiro.

Lerman, P., Apgar, D.H., \& Jordan, T. (2005). Longitudinal Changes in Adaptive Behavior of Movers and Stayers: Findings from a Controlled Research Design. Mental Retardation, 43, 25-42. http://dx.doi.org/10.1352/0047-6765(2005)43<25:LCIABO>2.0.CO;2

Luckasson, R., \& Schalock, R. (2012). The Role of Adaptive Behavior in a Functionality Approach to Intellectual Disability. In Santos, S., \& Morato, P. (Eds.), Comportamento Adaptativo-10 anos depois (pp. 9-17). Edições FMH. Faculdade de Motricidade Humana. Universidade Técnica de Lisboa.

Nihira, K. (1999). Adaptive Behavior: A Historical Overview. In Schalock, R., \& Braddock, D. (Eds.), Adaptive Behavior and Its Measurement (pp. 7-14). Washington DC: American Association on Mental Retardation.

Nihira, K. (2012). AAMR Adaptive Behavior Scale: Its History. In Santos, S., \& Morato, P. (Eds.), Comportamento Adaptativo-10 anos depois (pp. 75-82). Edições FMH. Faculdade de Motricidade Humana. Universidade Técnica de Lisboa.

Nihira, K., Leland, H., \& Lambert, N. (1993). Adaptive-Behavior Scale-Residential and Community: Examiner’s Manual (2nd ed.). Pro-Ed.

Oliveira, R. (2009). Social Behavior in Context: Hormonal Modulation of Behavioral Plasticity and Social Competence. Integrative and Comparative Biology, 49, 423-440. http://dx.doi.org/10.1093/icb/icp055

Pestana, M., \& Gageiro, J. (2005). Análise dos dados para Ciências Sociais: A complementaridade do SPSS (5th ed.). Edições Sílabo.

Sadrossadat, L., Moghaddami, A., \& Sadrossadat, S. (2010). A Comparison of Adaptive Behaviors among Mentally Retarded and Normal Individuals: A Guide to Prevention and Treatment. International Journal of Preventive Medicine, 1, 34-38.

Saloviita, T. (2002). The Closure of Nastola Care Home: A Longitudinal Study on Desinstitutionlization. Scandinavian Journal of Disability Research, 42, 138-155. http://dx.doi.org/10.1080/15017410209510789

Santos, S., \& Morato, P. (2012). Comportamento Adaptativo: Dez anos depois. Edições FMH. Faculdade de Motricidade Humana. Universidade Técnica de Lisboa.

Santos, S., Morato, P., Costa, D., Duro, V., Saramago, F., \& Bruno, P. (2010). Comportamento Adaptativo, Dificuldades Intelectuais e Desenvolvimentais na população portuguesa: Replicação do estudo de 2007. Revista de Educação Especial e Reabilitação, 17, 79-102.

Sartawi, A., AlMuhairy, O., \& Abdat, R. (2011). Behavioral Problems among Students with Disabilities in United Arab 
Emirades. International Journal for Research in Education, 29, 1-15.

Schalock, R.L., Buntinx, W., Borthwick-Duffy, S., Luckasson, R., Snell, M., Tassé, M.J., \& Wehmeyer, M. (2007) User’s Guide: Mental Retardation: Definition, Classification and Systems of Supports (10th ed.). Washington DC: AAIDD.

Schalock, R.L., Borthwick-Duffy, S.A., Bradley, V.J., Buntinx, W.H.E., Coulter, D.L., Craig, E.M., Gomez, S.C., Lachapelle, Y., Luckasson, R., \& Reeve, A. (2010). Intellectual Disability-Definition, Classification, and Systems of Supports. AAIDD. $11^{\mathrm{a}}$ Edição, Washington DC.

Tassé, M., Schalock, R., Balboni, G., Bersani, H., Borthwick-Duffy, S., Spreat, S., Thissen, D., Widaman, K., \& Zhang, D. (2012). The Construct of Adaptive Behavior: Its Conceptualization, Measurement and Use in the Field of Intellectual Disability. American Journal of Intellectual and Developmental Disabilities, 117, 291-303. http://dx.doi.org/10.1352/1944-7558-117.4.291

Thompson, J.R., Bradley, V.J., Buntinx, W.H.E., Schalock, R.L., Shogren, K.A., Snell, M.E. et al. (2009). Conceptualizing Supports and the Support Needs of People with Intellectual Disability. Intellectual and Developmental Disabilities, 47, 135-146. http://dx.doi.org/10.1352/1934-9556-47.2.135 